\title{
THE INHERITANCE OF KERNEL WEIGHT IN A TRITICUM VULGARE CROSS
}

\author{
L. G. L. COPP \\ Crop Research Division \\ and \\ G. M. WRIGHT
}

Crop Research Division and Applied Mathematics Laboratory, Department of Scientific and Industrial Research, Christchurch, New Zealand

\section{INTRODUCTION}

Received 30.xi.5I

THE study of the inheritance of a complex character, such as yield in wheat, is made difficult by variation caused by differences in the environment, and by the effects of interaction of environment and genotype. Yield per plant may be resolved into a number of sub-characters, or components, which may not be independent in their genetic control (Mather, 1949). The major components, each capable of further resolution, are number of ears per plant, number of kernels per ear, and average weight of a single kernel. Kernel weight has been shown to be the least variable of these components (Smith, 1936).

Estimates of the numbers of genes which determine kernel weight differences in wheat have already been published. Jasnowski (1934, 1935), quoted by Boyce (1948), obtained evidence that certain lines differed by three pairs of genes. Worzella (1942) stated that the inheritance of kernel weight in a number of wheat (Triticum aestivum L.) hybrids was multigenic. Boyce (l.c.), in a preliminary study, by empirical methods, of the material described in the present paper, concluded that the $\mathrm{F}_{2}$ and $\mathrm{F}_{3}$ frequency distributions, and the difference in kernel weight between the two parents, were the result of the action of two or of three major gene pairs.

The plants were grown at the Wheat Researrh Institute, Lincoln, in $1943 / 44$, but a detailed analysis was not then carried out. Interest in the material was revived following the publication in I 949 of Marher's Biometrical Genetics.

\section{MATERIAL AND METHODS}

The material was one of four crosses used in a preliminary study of the inheritance of kernel weight (Boyce, l.c.), comprising the parents, $\mathrm{F}_{1}, \mathrm{~F}_{2}$ and reciprocal $\mathrm{F}_{3}$ generations of the Triticum vulgare cross (India $29, \mathrm{~S}_{155} 6 \times$ Crete 2, $\left.\mathrm{S}_{357}\right)$. Where $\mathrm{P}_{1}\left(\mathrm{~S}_{1556)}\right.$ was used as pollen parent the hybrid material was designated as $\mathrm{F}_{2} \mathrm{~A}$ or $\mathrm{F}_{3} \mathrm{~A}$. The parents were chosen for their high and low kernel weights from a collection of foreign varieties. The purity of the lines had been maintained for several years by sowing grain from ears which had been covered before 
anthesis. Each $\mathrm{F}_{3}$ plot of $5^{2}$ plants was the progeny of a single $\mathrm{F}_{2}$ plant. The positions of eight $F_{1}$ plots of 26 plants and eight $F_{2} A$ plots of $5^{2}$ plants were randomized among the $\mathrm{F}_{3}$ plots, which were not replicated. Parent plots of 26 plants were grown in random order after every second hybrid plot. Evenness of spacing and depth were obtained by sowing individual grains with a "Woodfield" dibber. The grains were sown two inches deep, with eight inches between the rows of thirteen plants four inches apart.

Plants were harvested individually. For each plant the number of ears $(e)$, total number of kernels $(e n)$, and the yield $(e n g)$ were recorded; the average number of kernels per ear $(n)$ and the average weight of one kernel $(g)$ were calculated. Kernel weights for each plant were expressed in milligrams, and ranged from 20 to $6 \mathrm{r}$.

Plants with only one ear, or with fewer than forty kernels (about five per cent of those harvested in each population), were omitted from the analysis because average kernel weight would not have been determined with the same accuracy for these plants as for the rest of the material, and because, in many of them, the grain was shrivelled through disease or poor development. The analysis, therefore, is based on healthy plants only.

In studies of quantitative inheritance the amount of material is usually limited, and to obtain the maximum information (from the segregating populations) relatively small parent and $F_{1}$ populations are grown. The size of the $F_{1}$ is also limited by the work involved in crossing. For any character, all population frequency distributions are commonly presented in one figure. If the same frequency scale were used for all populations it would be difficult to make visual comparisons between them because the differences between the sizes of the popu-

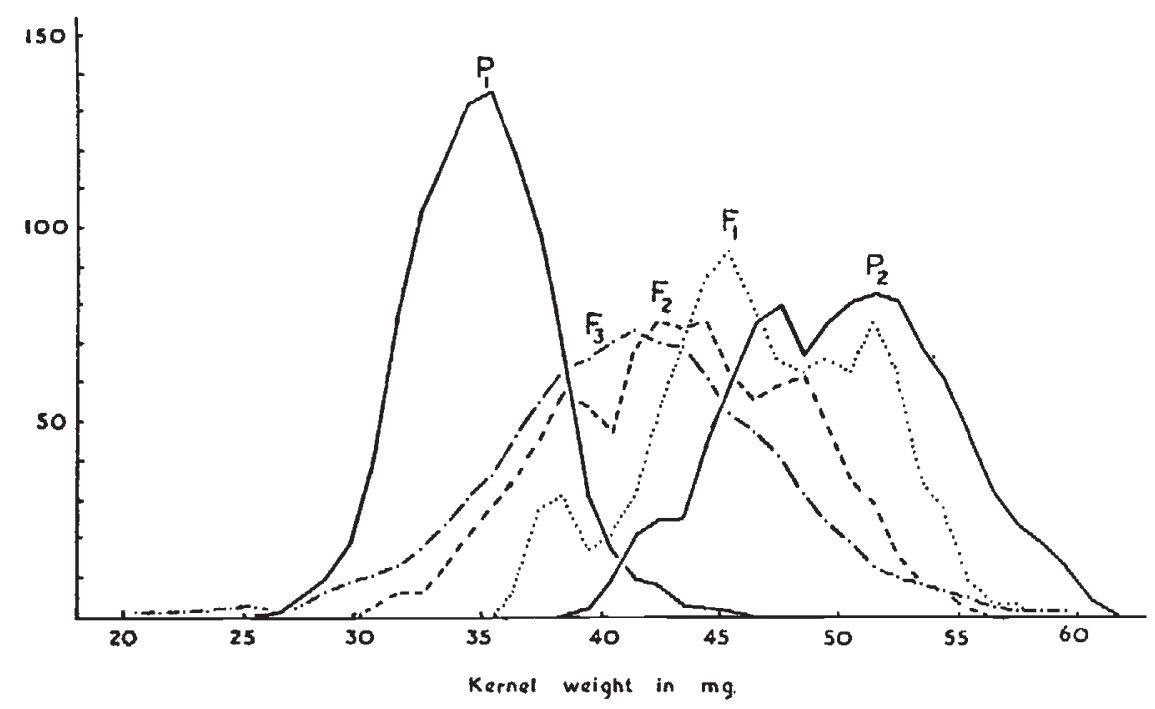

FIG. I,-Frequency distributions adjusted to equal population size. 


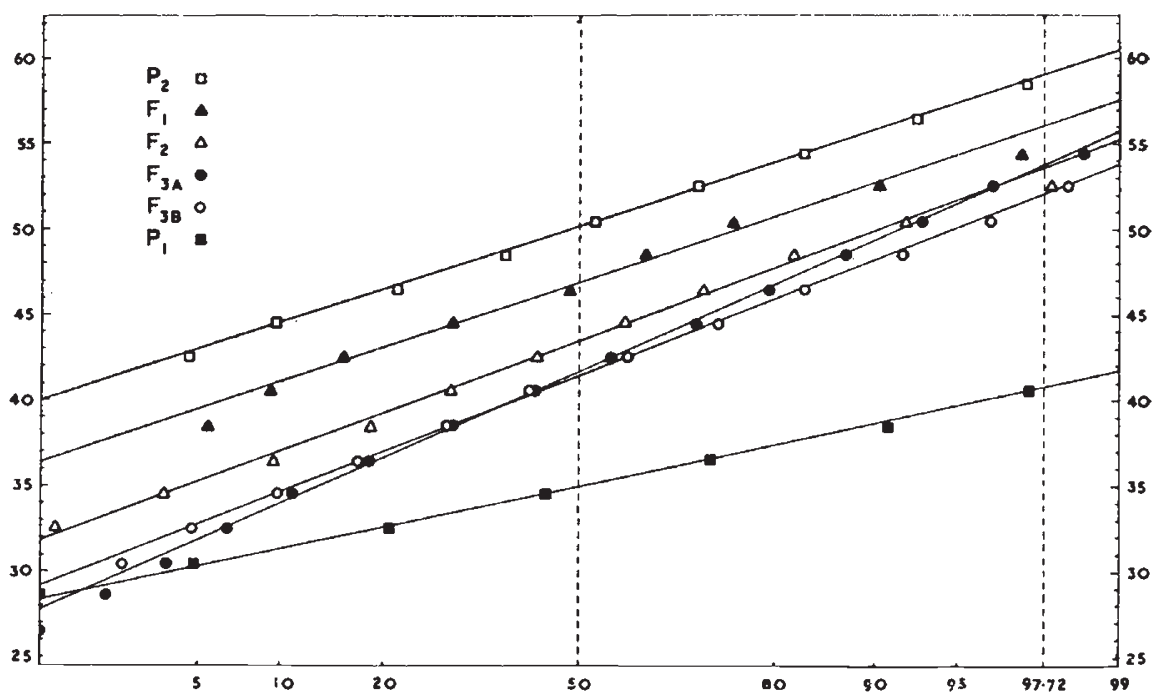

FIG. 2.-Cumulative frequency distributions of kernel weight on probability scale. The mean is located on the ordinate at $50 \%$. The standard deviation is proportional to the slope of the line.

lations are large. A second method, still complicated, in small populations, by the relation between range and population size, would be to adjust the populations to equal total frequencies. In figure I a twoterm moving average of adjusted kernel weight frequencies has been plotted.

A limitation to these methods of presenting the data is the difficulty experienced in distinguishing and comparing the population means and variances, but on a cumulative probability scale, by which normal distributions are represented by straight lines, the means and variances of the populations are easily compared. In figure 2, which was drawn on probability graph paper, there is, for each population, a point for every second unit of kernel weight over the population range. The numbers of plants in each kernel weight group were accumulated from the lower end of the range and the figures so obtained were expressed as percentages of the total number of plants. These percentages were plotted on the probability scale against the kernel weight, at the midpoints of the class intervals. For example, the percentage with kernel weight 44 or less (which means, in fact, less than 44.50 ) was plotted at 44.5 : if it were plotted at $44^{\circ} \mathrm{O}$ and the other points were plotted similarly, the mean, read off at the 50 per cent point, would be one half of the unit of measurement, or $0.5 \mathrm{mg}$., below the calculated mean. This method of presentation was used by Keller and Li (1949), who did not make this adjustment.

The normal distributions fitting each population are depicted in figure 2 as straight lines fixed by plotting the population mean at $50 \%$ probability, and the point twice the standard deviation above the mean at $97.72 \%$ probability. 


\section{RESULTS}

\section{(i) Description of Populations}

The populations had distributions close to normal (figure 2). The six population means and variances and some correlations of the raw data are given in table $1 a$. The parent $\left(\mathrm{S}_{357}\right)$ with the higher kernel

TABLE I

Population Statistics

(a) Average kernel weight ( $\mathrm{g}$ ); mg. per grain

\begin{tabular}{|c|c|c|c|c|c|c|}
\hline Generation & $\mathbf{P}_{1}$ & $\mathbf{P}_{2}$ & $\mathbf{F}_{1}$ & $\mathbf{F}_{2} \mathbf{A}$ & $\mathbf{F}_{3} \mathbf{A}$ & $\mathbf{F}_{3} \mathbf{B}$ \\
\hline Mean per plant & $34 \cdot 9^{6}$ & $50 \cdot 10$ & $46 \cdot 88$ & $43.4 \mathrm{I}$ & $4 x \cdot 59$ & $4 x \cdot 40$ \\
\hline Standard error of mean & $\begin{aligned} 0.14 \\
0.11\end{aligned}$ & 0.1 & $0 \cdot 37$ & $\begin{array}{l}75.41 \\
0.31\end{array}$ & 0.106 & 0.097 \\
\hline deviation & $2 \cdot 86$ & $4 \cdot 36$ & $4 \cdot 5$ & $5 \cdot 0$ & 6.025 & $5 \cdot 28 \mathrm{I}$ \\
\hline $\begin{array}{l}\text { Variance between plots. } \\
\text { Variance within plots }\end{array}$ & $\begin{array}{l}4{ }^{\cdot} 4^{8 * *} \\
5^{*} 80\end{array}$ & $\begin{array}{l}13 I^{\cdot} \cdot 98^{* *} \\
12^{*} 4^{8}\end{array}$ & $\begin{array}{l}34 \cdot 80 \\
19 \cdot 91\end{array}$ & $\begin{array}{l}71 \cdot 29^{* *} \\
23 \cdot 78\end{array}$ & $\begin{array}{c}481 \cdot 90^{* * *} \\
22 \cdot 04\end{array}$ & $\begin{array}{l}283.4^{8 * *} \\
20.06\end{array}$ \\
\hline $\begin{array}{l}\text { Parent-oftspring } \\
\text { correlation }\end{array}$ & & -0.264 & - & - & $0.737^{* *}$ & $0 * 43^{8 * *}$ \\
\hline Number of plots & & 4 & 8 & 8 & & 64 \\
\hline Number of plants & 497 & 711 & 143 & 242 & 1968 & 2120 \\
\hline
\end{tabular}

(b) Transformed variate: $\log ^{2}(g-25)$

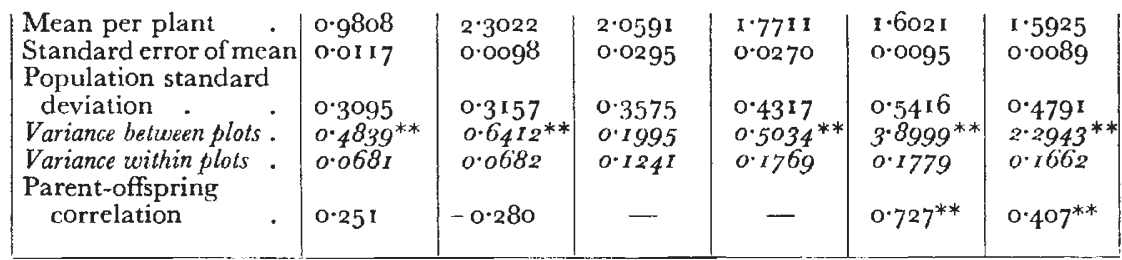

weight had a greater variance within plots than the other parent $\left(\mathrm{F}=2 \cdot \mathrm{I} 5^{* *}\right)$, but there was no correlation between plot means and variances in any population. Accordingly, the linear scale of measurement would be considered satisfactory for descriptive purposes. However, for a biometrical analysis of the data, the scale should be such that gene effects appear additive (Mather, I949, ch. 3) and such that there is no apparent interaction of environment and genotype. The fulfilment of these conditions depends on the positions of the $F_{2}$ and $F_{3}$ means in relation to those of the parents and $F_{1}$, and on the comparison of the variances of the three genetically homogeneous populations, $\mathrm{P}_{1}, \mathrm{P}_{2}$, and $\mathrm{F}_{1}$.

$$
\begin{aligned}
& \text { From table } r a \text {, Mather's } C=4 \overline{\mathbf{F}}_{\mathbf{2}}-2 \overline{\mathbf{F}}_{\mathbf{1}}-\overline{\mathbf{P}}_{1}-\overline{\mathbf{P}}_{2}=-5 \cdot 3 \\
& \text { and } D=8 \overline{\mathbf{F}}_{3}-2 \overline{\mathbf{F}}_{1}-3 \overline{\mathbf{P}}_{1}-3 \overline{\mathbf{P}}_{2}=-16 \cdot 3
\end{aligned}
$$

and using variances within plots $V_{C}=2 \cdot 16$ and $V_{D}=\mathrm{I} \cdot 48$, so that $C$ and $D$ (hence $\overline{\mathbf{F}}_{2}$ and $\overline{\mathbf{F}}_{3}$ ) were significantly lower than would be expected if gene effects were simply additive. In fact, $\overline{\mathbf{F}}_{\mathbf{3}}$ was slightly, and significantly, lower than the mid-parent. 


\section{(ii) Scaling}

It may be seen also that the within plot variances of $P_{1}, P_{2}$ and $F_{1}$ were unequal, so that neither criterion for the scale was satisfied. In the $F_{1}$, more than the scale was at fault, for the plot variances were not homogeneous. A suitable foreshortening scale would equalise the parent variances and improve the relative positions of the means, although it would affect the normality of the distributions. A square root scale was not sufficiently powerful. It was decided to use a modified logarithmic transformation deduced as follows: writing $\bar{G}=\log _{10}(\bar{g}-a)$ for $\bar{g}$ in the expressions for $C$ and $D$ above, where $g$ is the original kernel weight, $G$ the weight on the scale to be found, $a$ a constant to be determined, it was found that $C$ changed sign for $a$ between 25 and 30 , and $D$ for $a$ between 20 and 25 , so that $\log (g-25)$ seemed a satisfactory variate for analysis. The use of $\log (\bar{g}-a)$ rather than the mean of $\log (g-a)$ in calculating $C$ and $D$ made the approximate determination of $a$ feasible. Unfortunately, on this scale the $\mathrm{P}_{1}$ variance was higher than that of $\mathbf{P}_{2}\left(\mathbf{F}=3 \cdot 10^{* *}\right)$, and as a compromise a less powerful transformation was needed. Use of $\log (g-\mathrm{I} 0)$ equalised the parent variances but was not satisfactory for the means, $\log ^{2}(g-25)$ gave a smaller variance ratio $\left(\mathrm{F}=\mathrm{x} \cdot 3^{* * *}\right)$ for the parents than did $\log (g-25)$, and by extrapolation $\log ^{\frac{2}{2}}(g-25)$ was thought likely

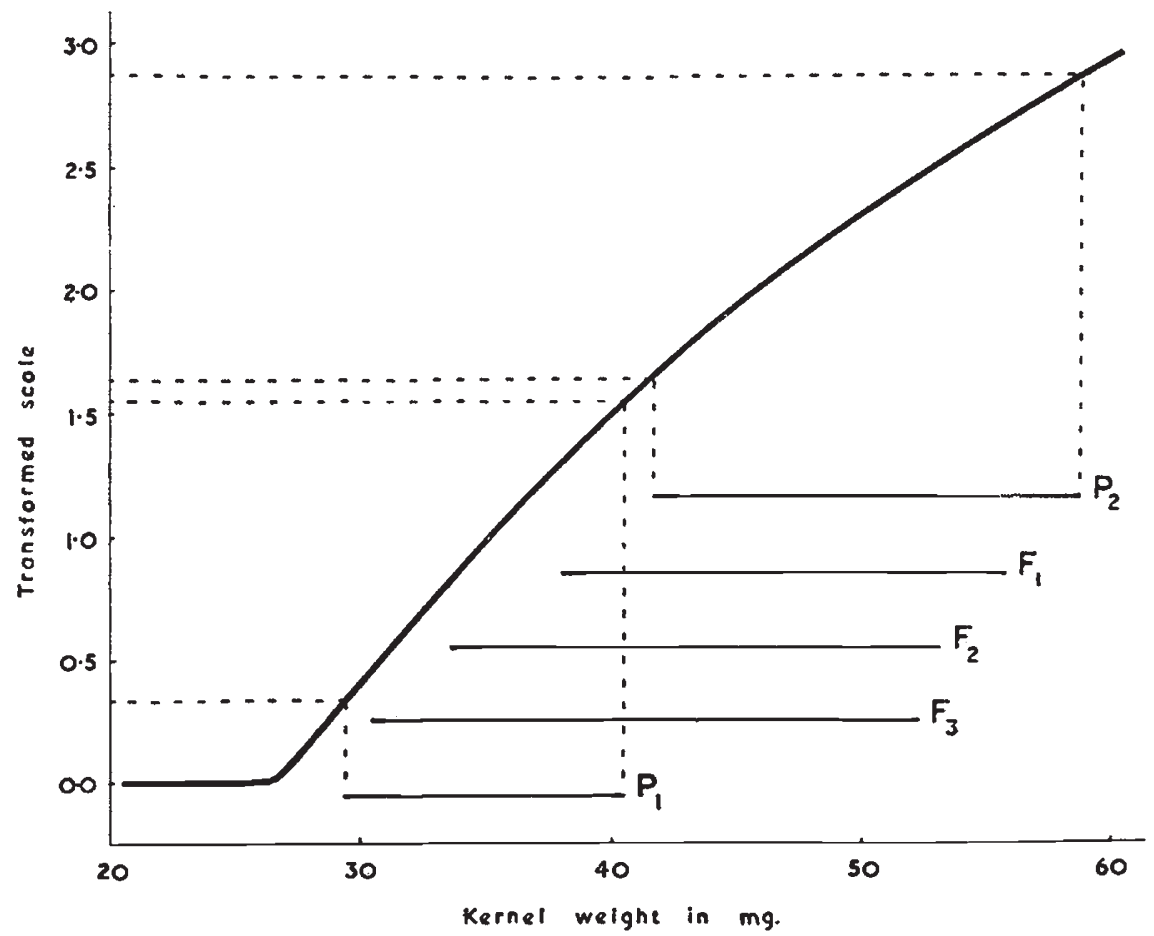

FIG. 3.-Graph of the function $y=\log 5(g-25)$ for transforming kernel weight figures. Ranges covering 95 per cent of the population distributions. $\mathbf{P}_{1}$ and $\mathbf{P}_{2}$ ranges are shown on both scales. 
to be adequate. This function is plotted in figure 3 . The ratio of parent variances with this transformation was $\mathrm{I} \cdot \mathrm{O} 4$.

Final calculations of $C$ and $D$ gave -0.317 and $-1 \cdot 13^{8}$, with variances respectively 3.46 and $12 \cdot 82$, which is satisfactory though the $\mathrm{F}_{3}$ mean is still slightly below the mid-parent. Once it has been decided to use a particular, arbitrary, transformation, its theoretical form is of little interest. It is unlikely that the same transformation would have been appropriate in another year, as in both the preceding and following years the average kernel weights of the parent varieties, grown in the same locality, were significantly higher.

\section{(iii) Transformed Data}

The statistics derived from the transformed data are shown in table $\mathrm{i} b$.

As already stated, the $F_{2}$ and $F_{3}$ means are now closer to their expected positions in relation to the means of the parents and $F_{1}$. The within-plot variances of the parents have been equalised. The $F_{1}$ variances, based on only 143 plants, have not been used in the biometrical analysis because they are still significantly different from those of the parents. The transformation has had no appreciable effect on variance ratios or on the parent-offspring correlations. Except in $\mathrm{F}_{1}$, the between-plot variances are highly significantly greater than those within plots. The large variance between plots of the parents is attributed to soil heterogeneity.

The $\mathrm{F}_{2}$ variance between plots is similar to those of the parents, the only genetic differences between $F_{2}$ plots being due to sampling. The within-plot variances of the $F_{2}$ and $F_{3}$, which express genetic variation, are much larger than those of the parents.

Although there is no significant difference in average kernel weight between the reciprocal $\mathrm{F}_{3}$ populations, their statistics have been presented separately. There are differences in the parent-offspring correlations and in the between-plot variances: the former difference is significant, and the latter almost significant, at 5 per cent. A highly significant difference between the reciprocal $\mathrm{F}_{3}$ 's in average number of kernels per ear is not discussed in the present paper. In the previous year six $F_{2}$ plots of approximately 60 plants had been grown, three $F_{2} A$ and three $\mathrm{F}_{2} \mathrm{~B}$. A random selection of these plants was used for the $\mathrm{F}_{3}$; their average kernel weights for $A$ and $B$ were similar to those of the remaining plants. The over-all variance of the $\mathrm{F}_{2} \mathrm{~A}$, as of the sample grown, was considerably greater than that of the $\mathrm{F}_{2} \mathrm{~B}(\mathrm{~F}=\mathrm{I} \cdot 37$, significant at 5 per cent). This difference, for which there is no explanation, would have contributed to the difference in $F_{3}$.

(iv) Biometrical Analysis

(a) Components of Variation

The second-degree statistics of segregating populations are functions of $D, H$ and $E$, which are components of variation dependent on the 
fixable and the unfixable genetic variation and the environmental variation respectively. The required statistics have the following expression (Mather, l.c.):

$$
\begin{aligned}
V_{F 2} & =\frac{1}{2} D+\frac{1}{4} H+E_{1}, \text { the within plot variance of } \mathrm{F}_{2} \text { plants, } \\
V_{\overline{F 3}} & =\frac{1}{2} D+\frac{1}{16} H+E_{2}, \text { the variance of } \mathrm{F}_{3} \text { progeny means, } \\
W_{F 2} /{ }_{F 3} & =\frac{1}{2} D+\frac{1}{8} H, \text { the covariance of } \mathrm{F}_{2} \text { plants of the previous year } \\
\text { with their progeny means, } & \\
\bar{V}_{F 3} & =\frac{1}{4} D+\frac{1}{8} H+E_{1}, \text { the mean variance of the } \mathrm{F}_{3} \text { progenies. }
\end{aligned}
$$

$E_{1}$ and $E_{2}$ are the non-heritable components of variation for single plants and for means of plots, estimated directly from the non-segregating populations. The least squares calculation of $D, H, E_{1}$ and $E_{2}$ from these six relations is described by Mather (p. 65). The observed " $\mathrm{A}$ " and " $\mathrm{B}$ " second-degree statistics and their averages, and the calculated values of $D, H, E_{1}$ and $E_{2}$ are presented in table 2.

\section{TABLE 2}

Observed second degree statistics, derived estimates of genetic and environmental components, and number of effective factors

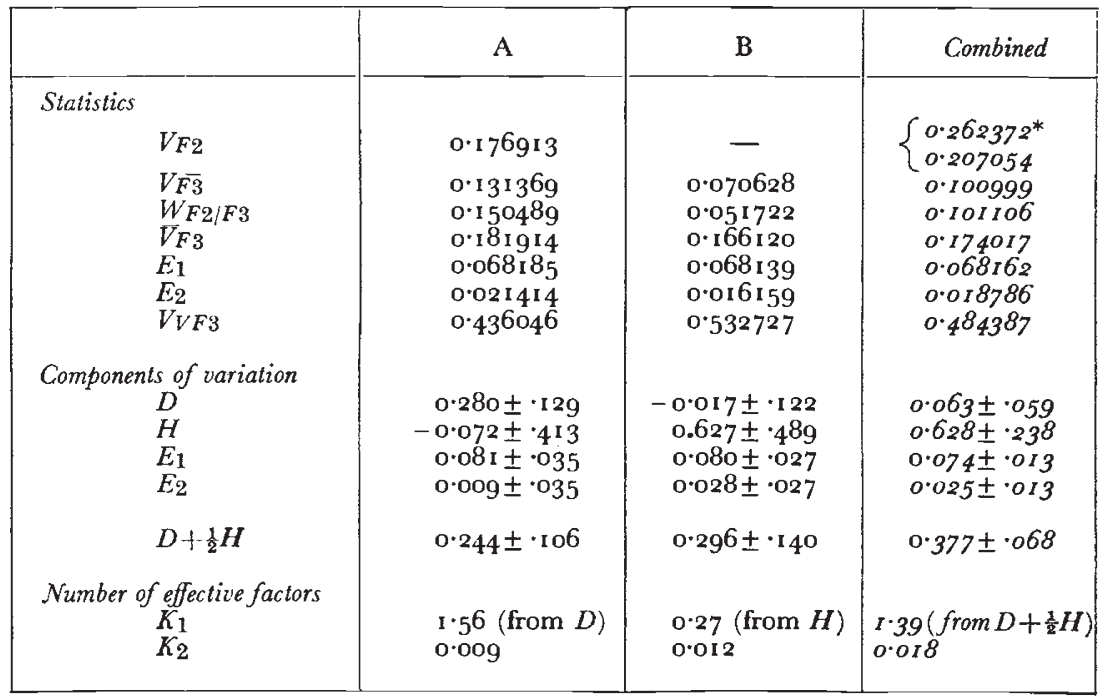

* These two figures are estimated from $D, H$, and $E_{1}$, from the "combined " estimates and the "restricted" linkage estimates respectively. There was no "observed" figure.

For the separate "A" and " $\mathrm{B}$ " analyses the component $E_{1}$ was estimated directly as the within-plot variance of $\mathrm{P}_{2}$ or $\mathrm{P}_{1}: E_{2}$ was estimated as the between-plot variance of $\mathrm{P}_{2}$ or $\mathrm{P}_{1}$, divided by the harmonic mean (29.94) of the numbers of plants per $F_{3}$ plot. Since no $F_{2} B$ was grown, for the " $B$ " and " combined" calculations it was necessary to prepare and invert a new matrix of coefficients. This matrix and its inverse are given in table 3 . 
TABLE 3

$$
\begin{aligned}
& \begin{array}{c}
\text { Matrix used in "B" and " combined" analyses in calculating } \\
D, H, E_{1} \text { and } E_{2} \text { without } V_{F 2}
\end{array} \\
& \mathbf{M}=\frac{\mathrm{I}}{256}\left|\begin{array}{rrrr}
144 & 32 & 64 & 128 \\
32 & 9 & 32 & 16 \\
64 & 32 & 512 & 0 \\
128 & 16 & 0 & 512
\end{array}\right|=\left|\begin{array}{llll}
0.5625 & 0.125 & 0.25 & 0.5 \\
0.125 & 0.03515625 & 0.125 & 0.0625 \\
0.25 & 0.125 & 2.0 & 0 \\
0.5 & 0.0625 & 0 & 2.0
\end{array}\right| \\
& M^{-1}=\frac{1}{25}\left|\begin{array}{rrrr}
416 & -1536 & 44 & -56 \\
-1536 & 6656 & -224 & 176 \\
44 & -224 & 21 & -4 \\
-56 & 176 & -4 & 21
\end{array}\right|=\left|\begin{array}{rrrr}
16 \cdot 64 & -61 \cdot 44 & 1 \cdot 76 j & -2 \cdot 24 \\
-61 \cdot 44 & 266 \cdot 24 & -8 \cdot 96 & 7 \cdot 04 \\
1 \cdot 76 & -8 \cdot 96 & 0 \cdot 84 & -0 \cdot 16 \\
-2 \cdot 24 & 7 \cdot 04 & -0.16 & 0.84
\end{array}\right|
\end{aligned}
$$

In table 2 it will be seen that the results from the "A" and " B " analyses are different, particularly with respect to the values of $H$. The "combined " analysis gave results very similar to the "B " analysis, but agreeing much more closely with the observed statistics. This similarity may be merely an effect of the omission of $F_{2}$ data. The components of variation were not accurately determined. (The " $A$ " standard errors have two degrees of freedom, the others one.) There is therefore little justification for their use in calculating the number of effective factors which differentiate the two parents, or the degree of dominance or potence shown. Mather has suggested that, in view of the negative correlation between $D$ and $H$ as shown in the two halves of the experiment, an estimate of $D+\frac{1}{2} H$ should be more consistent. The figures given in table 2 support this, and it will be scen that $D+\frac{1}{2} H$ is estimated with the same precision as $D$. The variance of the estimate depends on $\mathrm{C}_{D I D}, \mathrm{c}_{D H}$ and $\mathrm{c}_{H H}$ of the inverse matrix.

\section{(b) Test for Linkage}

A modification of Mather's " restricted" analysis, in which the mean variance of $F_{3}$ plots is omitted, is available as a test for linkage, though in the present material it would not be sensitive. In the "B" or "combined" analyses there would remain only four statistics involving $D, H, E_{1}$ and $E_{2}$, and thercfore no residual degrees of frcedom. If the calculated "combined" values of $D, H, E_{1}$ and $E_{2}$ are used to cstimate the second-degree statistics, as in calculating their standard errors, $V_{F 2}$ may be estimated also, and the eleven observed "A" and "B" statistics may be compared with these cstimates. The sum of squares of the eleven deviations, with seven degrees of freedom, is the total sum of squares in the linkage analysis. Similarly a set of statistics may be estimated from the "restricted" values of $D, H, E_{1}$ and $E_{2}$, giving the remaining value of $V_{F 2}$ in table 2. Since the four variance components were calculated from only four statistics, the remaining estimates are identical with the observed figures. The sum of squares of the eleven differences between these figures and the observed " $A$ " and " $B$ " statistics is a residual sum of squares; the difference between the total and the residual is the sum of squares, with one degree of freedom, for linkage. The ratio of the linkage and residual mean squares was $5.27\left(\mathrm{~F}_{\cdot 05}, 5 \cdot 99\right)$ which suggests that there is linkage between the 
genetic factors influencing kernel weight. However, in the absence of an $\mathrm{F}_{2} \mathrm{~B}$ this difference in variance cannot be attributed definitely to linkage.

\section{(c) Number of Effective Factors}

The number of "effective factors" differentiating the parents may be estimated by the use of components of variation and the parent and $\mathrm{F}_{1}$ means (Mather, l.c., p. I02). If $k$ effective factors have equal effects $d$, all in one direction, the expected value of $\left(\mathrm{P}_{2}-\mathrm{MP}\right)^{2}$ is $k^{2} d^{2}$, which equals $k D$, so that $k$ may be estimated as $K_{1}=\frac{\left(\mathrm{P}_{2}-\mathrm{MP}\right)^{2}}{D}$ and similarly, if $H$ is known accurately, $K_{1}=\frac{\left(\mathrm{F}_{1}-\mathrm{MP}\right)^{2}}{H}$, where $\mathrm{P}_{2}$ and $\mathrm{F}_{1}$ represent the corresponding averages and $2 \mathrm{MP}=\mathrm{P}_{1}+\mathrm{P}_{2}$. No precise estimate of $K_{1}$ can be obtained from this material; the best estimate is $\frac{2\left(\mathrm{P}_{2}-\mathrm{MP}\right)^{2}+\left(\mathrm{F}_{1}-\mathrm{MP}\right)^{2}}{2 D+H}$, which, using $(2 D+H)$ from the "combined" analysis, equals I.39. If, as is likely, the parents differed in many effective factors, an estimate of this order for $K_{1}$ would indicate incomplete concentration, the parents having both plus and minus allelomorphs. The data are compatible with a $K_{1}$ as large as twelve.

A second estimate, $K_{2}$, is derived from the variances of the $\mathrm{F}_{3}$ plots, as the ratio of the square of the heritable part of the mean variance of the $\mathrm{F}_{3}$ plots $\left(\frac{1}{4} D+\frac{1}{8} H\right)$ to a corrected variance of the plot variances ( $V_{V F 3}$, table 2; Mather, l.c., p. I04). This $K_{2}$ is expected to be smaller than $K_{1}$, except when $K_{1}$ is reduced by incomplete concentration, and the relative smallness of the $K_{2}$ as shown in table 2 would indicate, if the estimates were reliable and there were in fact many effective factors, that the factors have unequal effects on kernel weight. But the number of effective factors by which the parents differ remains undetermined, and, in consequence, no reliable estimate can be obtained of the immediate limits, or speed, of selective advance.

\section{(d) Difference between Reciprocal Crosses}

The components of variation estimated from the two halves of the experiment give two different estimates of the genetic difference between the parents. If the discrepancy is real (and the differences in components are certainly not significant) there is a difference between reciprocal crosses. There is a real difference in two of the seconddegree statistics, the greater range of the means of the $\mathrm{F}_{3} \mathrm{~A}$ plots partly explaining their higher covariance with their parent plants. Similarly, the variances of the $\mathrm{F}_{2} \mathrm{~A}$ progenies in the previous year were greater than those of $\mathrm{F}_{2} \mathrm{~B}$.

\section{(e) Results in Other Years}

The above analysis has been confined to the results obtained in I943/44, when the difference in kernel weight between the two parents 
was $15^{\cdot} \pm 0^{\circ} \mathrm{I}$. In the previous year, under much better growing conditions, the difference was $15 \cdot 9 \pm 0.3$, and the higher parent averaged $57 \cdot 3 \pm 0 \cdot 2$ (compared with $5^{0} \cdot 1 \pm 0 \cdot \mathrm{I}$ ). The relation of the $\mathrm{F}_{1}$ and $\mathrm{F}_{2}$ means to the parent means was similar in the two seasons. Three of the $F_{2}$ plants were selected for further study, two with average kernel weight slightly greater than $\mathrm{P}_{2}$ and one much lower than $\mathrm{P}_{1}$. Their $\mathrm{F}_{3}$ progenies, grown as part of the main experiment, had average kernel weights much closer to the $F_{3}$ mean than the original plants were to their $F_{2}$ mean, although the third progeny was again lower than $P_{1}$. The progenies of four plants from each of these $F_{3}$ plots were grown in the following year, again under good conditions, the $F_{3}$ plants in each plot being selected to cover the plot range of kernel weight, and averaging close to the plot average. In this $\mathrm{F}_{4}$ the kernel weights of the progenies derived from the two high $\mathrm{F}_{2}$ plants were all nearly as high as the high parent, which averaged $5 \mathrm{r} \cdot 7 \pm 0 \cdot 2$, but the progenies from the low $\mathrm{F}_{2}$ plant were significantly above the low parent. The original low $\mathrm{F}_{2}$ plant was apparently strongly affected by its environment, yet the single-plant selection in $\mathrm{F}_{2}$ was effective, and much more effective than selection in $F_{3}$. This would suggest that the number of effective factors by which the parents differed was not large.

\section{DISCUSSION}

In this experiment, as in some of those listed by Mather, the components of variation were not estimated precisely, although much material was grown. The design of the experiment did not satisfy all the requirements for biometrical analysis prescribed by Mather; the $F_{3}$ plots were not replicated, the $F_{2}$ and $F_{3}$ plots were twice as large as those of the $F_{1}$ and the parents, and the two parents were sown in random order at regular intervals. Only the first of these defects is serious, but it has been pointed out recently (Mather and Vines, unpublished) that more information will be obtained by the growing of a given number of unreplicated $\mathrm{F}_{3}$ families than from half that number in two replications.

The plots were arranged in eight adjacent blocks, but the parent plots showed no significant block differences. Block differences in the $\mathrm{F}_{3}$ would be confounded with genetic differences between plots. Replication is desirable, to supply a more precise estimate of the errors of the components of variation and for the test of linkage. Unfortunately, different numbers of plots of the $\mathrm{P}_{1}$ and $\mathrm{F}_{3}$ were harvested from each block, so that an analysis with eight "replicates" would not have been justified. The separation of the reciprocal crosses in the present material provided in the second-degree statistics a set of eleven deviations. The standard errors of the "combined" estimates of $D, H$, $E_{1}$ and $E_{2}$ derived from the deviations from the "combined" seconddegree statistics had only one degree of freedom. If the deviations from the separate "A" and "B " statistics had been used, there would have been seven degrees of freedom available, but the differences be- 
tween the reciprocal crosses were such that the test of significance of the components would not have been improved.

It was not possible to find a scale of measurement on which the parent variances would be equalised and the $\mathrm{F}_{3}$ means would be higher than the mid-parent, though on the scale adopted the $F_{3}$ was not significantly below its expectation. The form of the transformation is restricted mathematically only by the condition that it must be continuous and monotonically increasing over the range of expression. In studies of quantitative inheritance there is no reason to expect that one of the "standard" transformations will be the most appropriate. A biometrical analysis of the untransformed data led to conclusions similar to those presented; the transformation made the data conform more closely to the theoretical genetic criteria but its use has not provided more, or more precise, information. It might be suggested that the $F_{1}$ mean should have been ignored in testing the scale, since the $F_{1}$ plot variances were not uniform, but the mean itself was accurately known, and the $\mathrm{F}_{3}$ mean was still significantly below expectation based on $\mathrm{F}_{2}$ and parent means. The most satisfactory effect of the re-scaling, forced to equalise the within-plot variances of the parents, was the equalising of the between-plot variances of the parents and $F_{2}$. Their ratios were changed from I : $3 \cdot 18: I^{\prime} \cdot 72$ to I : I $33:$ I $\cdot 04$.

The difference between the reciprocal crosses affects the estimates of $D$ and $H$, but not $D+\frac{1}{2} H$. It has been stated that the difference may be attributable to a difference in the $\mathrm{F}_{2}$ of the previous year, but the origin of this difference is unknown. It is unfortunate that no $\mathrm{F}_{2} \mathrm{~B}$ was grown with the $\mathrm{F}_{3}$ 's. The original $\mathrm{F}_{2}$ difference might have been a consequence of differential incidence of seed-borne (and hence " maternally inherited ") disease in the first $\mathrm{F}_{1}$ plants.

In this material the weighting of the second-degree statistics was not conducive to the improvement of the estimates. Weighting the observations $\mathrm{E}_{1}$ and $\mathrm{E}_{2}$ heavily did not increase the accuracy of estimation, which suggests that the re-scaling had not removed all interaction of genotype with environment. A disadvantage of weighting is that the required matrix of coefficients is not one of the standard forms, and is not symmetrical. The standard matrices are relatively easy to invert by Fisher's method, particularly if the equations set up are cleared of fractions; the terms of the inverse matrices are found as fractions with a common denominator which is, apart from powers of two, the value of the determinant of the original matrix. Thus in Mather's table $\mathrm{I} 2$ (p. 6I) $\mathrm{c}_{\mathrm{HH}}$ is exactly $\frac{8704}{93}$, which equals $93.59 \mathrm{I} 398$, and not 93.59 I $44 \mathrm{I}$ as given.

Kernel weignt was shown by Smith (1936) to be the most effective yield component for differentiating between certain varieties of wheat. The present parents were chosen because they differed widely in average kernel weight: 98.6 per cent of the parent plants could be classified correctly on kernel weight alone, and about half of the remainder were 
classified correctly if number of kernels and number of ears were also taken into account.

Boyce (I948) showed that the shape of the $\mathrm{F}_{2}$ distribution of kerncl weight could be explained by the segregation of two partially dominant genes, but she was unable to find any satisfactory explanation for the $\mathrm{F}_{3}$ distribution. No doubt it would be impossible to get a statistically satisfactory fit in this large $F_{3}$ (Haldanc, 1949). Formal estimates of number of genes, or effective factors, are unreliable, but they arc valuable in indicating whether the effects of genes are equal and in the same direction. The data suggest that the effective factors influencing kernel weight are possibly linked, have unequal effects, and do not all act in the same direction.

Effectiveness of selection for yield componcnts may be less than for total yield (Boyce et al., I 947). In the material of Palmer (I952), although selection for kernel weight was effectivc, it had no effect on total yield, because kernel weight was negatively correlated with number of kernels per plant. The present $F_{4}$ data show that a line with kernel weight as high as the high parent is recoverable, and that it may be possible to select a line as low as the low parent. This information about the limits of selection is more definite than that obtained from the biometrical analysis.

The application of Mather's methods of analysis has not been successful. The variances and covariances of the segregating populations did not have the general relationships expected on simple genetic reasoning: the $\mathrm{F}_{2} / \mathrm{F}_{3}$ covariance was relatively high in the " $\mathrm{A}$ " material and low in the "B". There are several possible explanations. 'The difference between parental genotypes is fixed, but would have a differcnt expression in another environment. Some mistakes would have been made in counting, weighing and computing, and these would have increased the crror variances even if no bias were introduced. Non-heritable variation, sampling variation and residual genic interaction would have lowered the procision of the analysis. Sampling variation would be expected to be small in this large material, and non-heritable variation appears to have been adjusted by the re-scaling, leaving residual genic interaction as the most probable explanation for the lack of success. 'There is no suggestion that any other method of analysis would have given more information.

\section{SUMMARY}

1. The inheritance of kernel weight was studicd in the first threc hybrid gencrations of a varictal cross in Triticum vulgare, using the biometrical methods developed by Mather.

2. A transformation was derived by which the data satisfied Mather's two criteria for an adequate scale of measurement. The empirical method of obtaining the transformation, by means of the formulae for the tests of a scale, has been explained. 
3. 'The advantages of presenting a set of frequency distributions on probability graph paper have been discussed.

4. Although the material was large the estimates of the genetic and environmental components of variation were not sufficiently precise to enable any definite conclusions to be drawn regarding the number of effective factors segregating, their linkage relationships or the possible limits to selection. It has been suggested that residual genic interaction has affected the precision of the estimates.

5. There were unexplained differences between the distributions of the reciprocal $F_{3}$ progeny means, which produced differences between the separate estimates of the components of variation.

Acknowledgments.-The authors are indebted to Mrs S. W. Boyce, formerly of the Wheat Research Institute, who initiated this work, and who was responsible for the growing and harvesting of the material and the determination of the components of yield for the large number of individual plants. Miss E. Milne, Applied Mathematics Laboratory, has rendered invaluable assistance in the final reduction of the data.

\section{REFERENCES}

воYсE, s. W. 1948. A preliminary study of the inheritance of grain weight in wheat. N.Z.F.Sci. and Tech., 3o, 13-22.

BOYCE, s. W., COPP, L. G. L., AND FRANKEL, O. H. I947. The effects of selection for yield in wheat. Heredity, $I, 223-234$.

HALdANE, J. B. S. 1949. Some statistical problems arising in genetics. J. Roy. Stat. Soc. $B, X I, I-I 4$.

JAsiowski, s. I934. On the inheritance of weight in grains of $T$. vulgare L. Roczn. Nauk. Rolnicz. i Lesnyck, 33, 59-68.

JAsNow'ski, s. I935. On the inheritance of some characters of the ear of wheat. Polon. Acad. Bul. Sc. Lettres Carcovi, r99-2 18.

KELlER, K. R., AND LI, J. C. R. I949. The relationship between the number of vines per hill and yield in hops. Agron. $7 ., 4^{I}, 569-573$.

mather, k. 1949. Biometrical Genetics. London.

MATHER, K., AND VINES, A. Inheritance of height and flowering time in a cross of Nicotiana rustica. Heredity (in the press).

palmer, T. P. 1952. Population and selection studies in a Triticum cross. Heredity, (in the press).

Smith, H. FAIRfield. I936. A discriminant function for plant selection. Ann. Eugen., 8, 240-250.

WORZELLA, w. w. 1942. Inheritance and inter-relationship of components of quality, cold resistance and morphological characters in wheat hybrids. 7 . Agr. Res., $65,501-522$. 